\title{
Eye Appendage
}

National Cancer Institute

\section{Source}

National Cancer Institute. Eye Appendage. NCI Thesaurus. Code C32574.

Any accessory organ of the eye, including the eyelids, eyebrows, lacrimal apparatus, or conjunctiva. 